\title{
Outcomes of Fast-Track Multidisciplinary Care of Hip Fractures in Veterans: A Geriatric Hip Fracture Program Report
}

\author{
Vikas Kulshrestha, MS, Munish Sood, DNB, Santhosh Kumar, DNB*, Pramila Sharma, BSc ${ }^{\dagger}$, \\ Yash Kumar Yadav, BA ${ }^{\dagger}$ \\ Department of Orthopaedics, Command Hospital, Panchkula, \\ ${ }^{*}$ Department of Orthopaedics, Air Force Hospital, Bangaluru, \\ ${ }^{\dagger}$ Department of Orthopaedics and Rehabilitation, Air Force Hospital, Kanpur, India
}

Background: Hip fractures are a significant cause of morbidity and mortality in the elderly. Fast-track multidisciplinary co-management of these patients, rapid preoperative optimization, early surgery, and expeditious rehabilitation may minimize morbidity and mortality. In this study, we evaluated outcomes of fixation of hip fractures in the elderly patients managed by Geriatric Hip Fracture Program at a military hospital in India.

Methods: A total of 114 patients above 60 years of age with hip fractures were enrolled. They were comanaged by a team of specialists and fast-tracked to surgery. Independent ambulation with support of a walker was achieved before discharge to home. Patients were followed up for 1 year.

Results: The average age of the 114 patients was 77 years; 24 patients were octogenarian. Eighty-four percent of injuries were due to a domestic fall. Hypertension (41\%) and diabetes (22\%) were the most common comorbidities. All patients were optimized before surgery. The average delay from injury to admission was 1.7 days (range, 0 to 14 days) and that from admission to surgery was 1.8 days (range, 0 to 19 days). Hence, the average time from injury to surgery was 3.5 days. The length of stay in hospital was, as per rehabilitative milestones achieved, 2 to 5 days in $40 \%$ of the patients and 6 to 15 days in $60 \%$ of the patients. At 1 year after surgery, 95 patients were independently ambulant (56 patients with support and 39 patients without support). Twenty-three percent of the patients had postoperative complications and eight patients died (7.7\%) at 1-year follow-up; 11 patients were lost to follow-up.

Conclusions: Elderly hip fracture has a high risk of mortality (14\%-58\%). Thus, expeditious surgery within 24 hours of admission has been advocated in the Western literature to minimize mortality. Mortality rate at 1 year after surgery remains at $10 \%$ to $24 \%$. In our study, even with aggressive co-management, the average delay to hip fracture fixation was more than 3 days; however, the 1 -year mortality was relatively low (7.7\%). This indicates the importance of preoperative optimization and postoperative rehabilitation for independent ambulation and mortality reduction in the elderly population.

Keywords: Geriatric, Hip fracture, Co-management, Rehabilitation, Mortality

Received February 25, 2019; Accepted April 24, 2019

Correspondence to: Munish Sood, DNB

Department of Orthopaedics, Command Hospital, Chandimandir, Panchkula,

Haryana 134107, India

Tel: $+91-1724802188$

E-mail: soodmunishafmc@gmail.com
Geriatric hip fractures are a major public health problem. ${ }^{1,2)}$ This injury has been associated with large health care expenses and high 1-year mortality rates (14\%$58 \%){ }^{3,4)}$ Health care costs are substantially high for patients who require long-term care and do not return to the community. ${ }^{5,6)}$ Further, these patients have multiple 
Kulshrestha et al. A Geriatric Hip Fracture Program Report

Clinics in Orthopedic Surgery • Vol. 11, No. 4, $2019 \bullet$ www.ecios.org

comorbidities. In developing countries, because health care facilities are not available or unaffordable, the comorbidities are inadequately managed. Usually, these patients have delayed presentation (24-72 hours after injury) with missed meals and medications. Recumbency resulting from fracture decompensates them. After initial care in the intensive care facility, these patients require multiple crossreferrals and preoperative optimization of health before safe surgery can be undertaken. Current Western literature recommends expeditious surgical care (within 24 hours) of hip fractures in elderly patients for optimal outcomes and decreased mortality. ${ }^{4,7}$ In developing countries, however, often there is a surgical delay, which may affect the achievement of optimal outcomes.

Most medical centers worldwide are trying to expedite (24-72 hours) the hip fracture surgery in elderly patients. However, there is conflicting literature wherein some studies have shown patient optimization before surgery is a more important determinant of early mortality rate than time to surgery is. Restoration of mobility and ability to perform activities of daily living (ADL) independently at home has also been shown to affect 1-year mortality. ${ }^{7)}$ We instituted Geriatric Hip Fracture Program (GHFP) at our hospital in January 2016. It incorporated three elements: rapid optimization with co-management, early surgery, and restoration of independent ambulatory ability (in our in-hospital rehabilitation facility) before discharge of patients for home care. We initiated the Geriatric Hip Fracture Registry, in which data that would help us study the effect of the program was recorded. The primary objectives of our study were to investigate the 1-year mortality in patients with hip fracture operated at our center after the institution of GHFP and to compare the rate with that in the current Western literature. Our secondary objective was to evaluate their ambulatory ability at 1 year after surgery. We also examined the perioperative complications and readmissions.

\section{METHODS}

This was a prospective cohort study. After obtaining local ethics committee approval of Air Force Hospital Kanpur (02/EC/ICMM/AFH/2016), we screened all patients who were more than 60 years of age, presented to our hospital with acute hip fracture (neck of the femur and trochanteric region), and were willing to participate in the study. Excluded patients were those who presented more than two weeks after injury, had a periprosthetic/pathological fracture, or were not independently mobile with or without support because of the prior neuromuscular or skeletal condition. We informed the enrolled patients and their family of the need to follow up with us till 1 year after surgery. In case of any difficulty in reporting to the hospital, we conducted a phone call follow-up.

\section{Key Elements of Our GHFP}

The management of hip fractures entails complex yet cohesive care from presentation to the emergency department, through departments of radiology, anesthesia, orthopaedic surgery, medicine, and rehabilitation. Techniques to expedite preoperative care can shorten operative delays. An orthopaedic matron (PS) was designated as the dedicated trauma coordinator for fast tracking patients with hip fractures to surgery. She was responsible for organizing the operating room lists and perioperative care, securing hospital beds, and acting as a liaison with the radiology department, an orthopaedic surgeon, a physician, an anaesthetist, an operating room matron, physiotherapists, and porting services. Nursing and emergency room staff was well acquainted with special needs and protocols of GHFP. When a patient with suspected hip fracture arrived at the casualty room of our hospital, immediate communication to an orthopaedic surgeon, the orthopaedic matron, a physician, an anaesthetist, operating room assistants, and physiotherapists was ensured. By the time the patient was admitted, all cross-referrals were done and patient optimization was started simultaneously with anaesthetic evaluation for early surgery in an appropriate risk grade. On admission of a patient, the orthopaedic matron confirmed early baseline hematological and biochemical values, blood products were crossmatched and kept ready, and the next of kin (NOK) was consulted regarding the operative procedure-medicolegal, physical, and psychological preparation, rehabilitation milestones, home care needs, and discharge protocol. Transferring the patient to the operation theatre with trauma precautions after initial stabilization was done at the earliest. Under the program, with mutual consent of the anaesthetist, the medical specialist, and the orthopaedic surgeon, the patient with nonmodifiable risk factors were not overinvestigated to avoid unnecessary delay in surgery and were taken up for fracture fixation under an appropriate risk grade. Hence, most of the patients were operated within 24 hours of arrival at the hospital. For patients with modifiable risks that require optimization, expeditious management was started in 24 to 48 hours. The common comorbidities resulting in a delay were dehydration and electrolyte imbalance, unoptimized diabetes mellitus, and chronic obstructive pulmonary disease.

For fixation of these fractures, state-of-the-art im- 
Kulshrestha et al. A Geriatric Hip Fracture Program Report

Clinics in Orthopedic Surgery • Vol. 11, No. 4, $2019 \bullet$ www.ecios.org

plants were used with principles of minimally invasive surgery to decrease surgical scars. All fractures requiring fixation were operated under the guidance of an image intensifier on the traction table. The fractures was reduced in a closed manner, and a small incision was used to fix the fracture with an intramedullary device without opening of the fracture site. The average duration of surgery was 44 minutes ( \pm 18 minutes) with less than $200 \mathrm{~mL}$ of blood loss. Patients received an injection of Cefazolin $2 \mathrm{~g}$ 1 hour before surgery, which was followed by another injection of $2 \mathrm{~g}$ at 12 hours after surgery. If urinary catheterization was required, aminoglycoside (adjusted dose) was administered as prophylaxis before catheter insertion, and a levofloxacin tablet $500 \mathrm{mg} /$ day was administered for 5 days. Special care was taken to avoid electrolyte imbalance, hypotension, renal insult, deep vein thrombosis, and bedsore. In view of patients' age and comorbidities, we avoided the use of narcotics and sedatives. An aggressive physical therapy protocol with mechanical and chemical prophylaxis was used: weight-adjusted prophylactic dose of enoxaparin injection till discharge followed by a rivaroxaban tablet $10 \mathrm{mg} /$ day till 5 weeks after surgery for prevention of venous thromboembolism. We encouraged early ambulation (within 24 hours after surgery) and permitted discharge only after the patient could walk with a walker and perform ADL with reasonable independence. The NOK was trained for ambulatory needs of the patients and home care.

A very important part of our program was effective NOK counselling. An extended period of hospital stay of the elderly patients leads to not only increased rates of complications but also tremendous socioeconomic burden on the society. To ensure rapid discharge and early rehabilitation, we started NOK and caretaker counselling from admission. The aim was to allay all anxiety of the NOK and involve them in the care of the patient from the beginning. This ensured that we were able to effectively rehabilitate the elderly patients back into the community at the earliest. The NOK was educated about the needs of the elderly in terms of physiotherapy, diet, medications, and general nursing care required at home. The physician, nursing staff, physiotherapist, and dietician would counsel

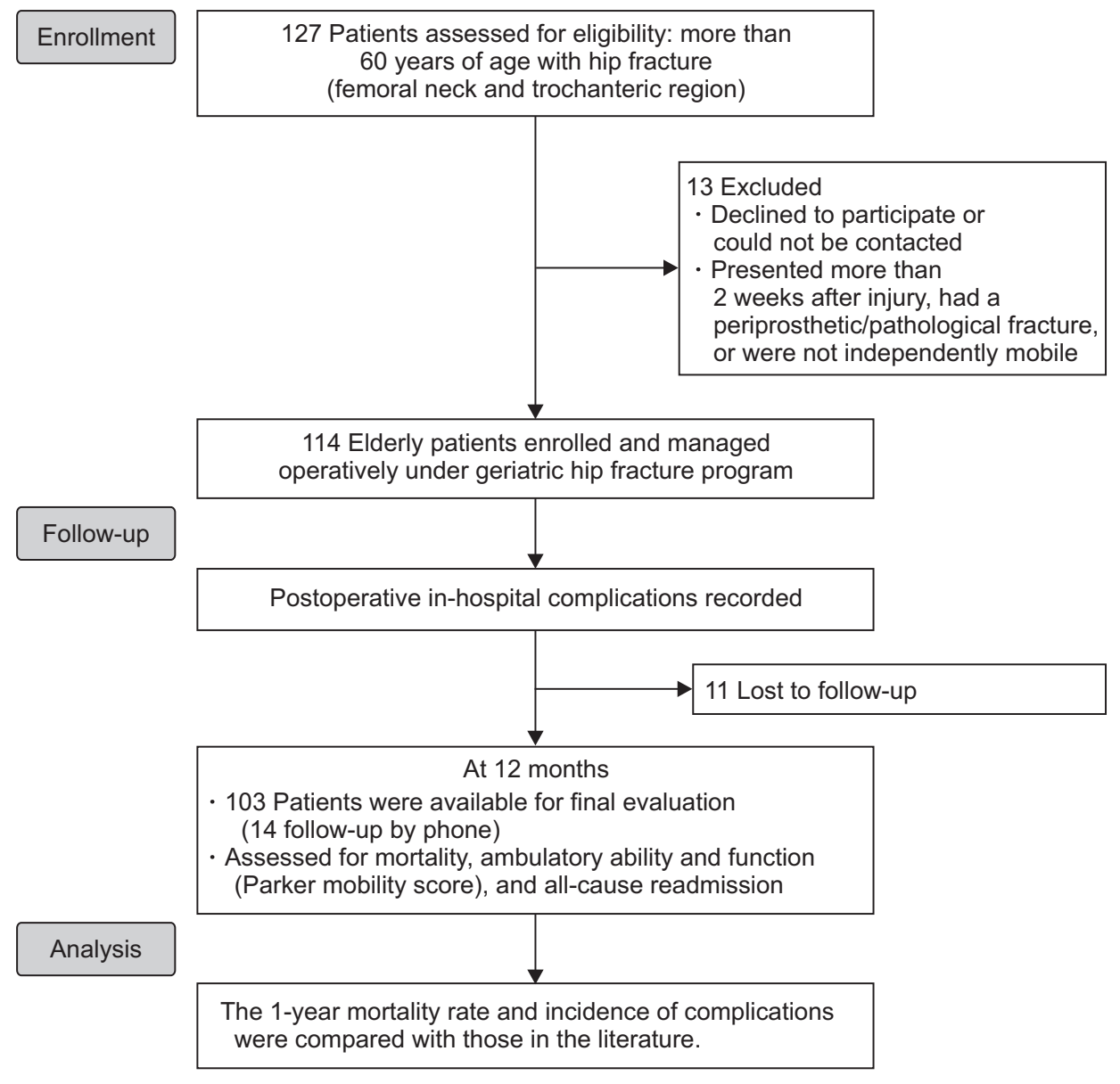

Fig. 1. Patient enrollment and follow-up flowchart. 
Kulshrestha et al. A Geriatric Hip Fracture Program Report

Clinics in Orthopedic Surgery • Vol. 11, No. 4, $2019 \bullet$ www.ecios.org

the patient and NOK to ensure early discharge and minimum readmissions in these patients.

\section{Data Collection}

A dedicated multidisciplinary team of physicians-sur-

\section{Table 1. Age Distribution, Comorbidities, and FCl in the Patients Enrolled for the Study}

\begin{tabular}{|lc|}
\hline \multicolumn{1}{|c}{ Variable } & Value \\
\hline Age distribution (yr) & \\
\hline $60-70$ & $53(46)$ \\
\hline $71-80$ & $42(37)$ \\
\hline$>80$ & $19(17)$ \\
\hline Comorbidity & \\
\hline No associated comorbidity & 32 \\
\hline Anaemia & 56 \\
\hline Hypertension & 35 \\
\hline Diabetes mellitus & 14 \\
\hline Hypertension with diabetes mellitus & 12 \\
\hline Chronic obstructive pulmonary disease & 9 \\
\hline Coronary artery disease & 6 \\
\hline Pulmonary tuberculosis & 0 \\
\hline Chronic liver disease & 0 \\
\hline Hypothyroidism & 6 \\
\hline Neurological disorder & 6 \\
\hline Bronchial asthma & 2 \\
\hline Chronic kidney disease & 4 \\
\hline Psychiatric disorder & 14 \\
\hline Miscellaneous & 12 \\
\hline FCl & 73 \\
\hline No. of diseases & \\
\hline 1 & \\
\hline 2 & \\
\hline 3 & \\
\hline 4 & \\
\hline 5 & \\
\hline 6 & \\
\hline
\end{tabular}

Values are presented as number (\%) or number.

FCl: Functional Comorbidity Index. geons, anesthetists, nursing coordinators and physiooccupational therapists-ran the GHFP. We recorded demographic and injury characteristics of the patients, including delay to definitive surgery. Predefined perioperative complications and all serious adverse effects were meticulously recorded. The patients were followed up for 1 year (through visits to the outpatient department and phone calls) to look for all causes of readmission, mortality, and ambulatory status using the Parker mobility score (Fig. 1). At the final follow-up, we compared our results with those of the existing literature.

\section{RESULTS}

A total of 114 elderly patients (age $>60$ years) with hip fractures were enrolled from January 2016 to December 2016. The mean age of the patients was 77 years. There were 58 men and 56 women. Most of the patients had multiple comorbidities with an average Functional Comorbidity Index (FCI $)^{8)}$ of 1.7 (Table 1). Thirty percent of patients had hypertension and $23 \%$ had diabetes mellitus. Less than $10 \%$ of the patients had chronic obstructive lung disease (7\%) and ischemic heart disease (5\%). In $88 \%$ of the patients, the surgery was done within 48 to 72 hours of injury; however, more than $50 \%$ of patients were brought only after 48 hours of injury. The average time from injury to surgery was 3.5 days (Table 2). In $12 \%$ of patients, surgery was delayed beyond 7 days because they either arrived late or needed extended time for optimization. Eighty-four percent of hip fractures were due to a domestic fall. Sixty-eight patients required fracture fixation and 46 underwent hip arthroplasty. In $40 \%$ of the patients, the average length of stay was 2 to 5 days; however, in $60 \%$, the stay was extended from 6 to 15 days because of complications in a few patients and need for extended rehabilitation for performing $\mathrm{ADL}$ in some patients. The average length of stay of these patients was 7.6 days. Fourteen of the 114 patients (12\%) needed readmission in the first three months of follow-up. The most common complication was wound complication, followed by dyselectrolytemia (4\%)

\begin{tabular}{|c|c|}
\hline Variable & Mean (range) \\
\hline Time from injury to admission (day) & $1.7(0-14)$ \\
\hline Time from admission to surgery (day) & $1.8(0-19)$ \\
\hline Time from injury to surgery (day) & $3.5(0-19)$ \\
\hline
\end{tabular}

\section{Surgery}


Kulshrestha et al. A Geriatric Hip Fracture Program Report

Clinics in Orthopedic Surgery • Vol. 11, No. 4, $2019 \bullet$ www.ecios.org

and postoperative confusion (3\%) (Table 3).

At 1 year after surgery, we could follow up 103 patients, 11 could not be contacted. There were eight mortalities (7.7\%): one in-hospital, five within 90 days, and the other two at 1-year follow-up. We evaluated the ambulatory status and functional ability of the 95 patients who were alive and thus could be followed up at 1 year. All patients were ambulant, $41 \%$ of the patients were ambulant unaided and 59\% needed ambulatory aid in the form of a walker or walking stick. Regarding the Parker mobility score, ${ }^{9)} 50 \%$ of patients were community ambulators and $45 \%$ were independent home ambulators with or without support. Only $5 \%$ of patients were dependent for their ADL.

\section{Table 3. Complications at 1-Year Follow-up}

\begin{tabular}{|c|c|}
\hline Variable & No. $(\%)$ \\
\hline \multicolumn{2}{|l|}{ Local complication } \\
\hline \multicolumn{2}{|l|}{ Wound } \\
\hline Surgical site infection & $4(4)$ \\
\hline Superficial incisional & $1(1)$ \\
\hline Prosthetic joint infection & $3(3)$ \\
\hline Dislocation & $2(2)$ \\
\hline \multicolumn{2}{|l|}{ Systemic complication } \\
\hline \multicolumn{2}{|l|}{ Neurological } \\
\hline Postoperative confusion & $3(3)$ \\
\hline Seizure & $1(1)$ \\
\hline Post spinal headache & $1(1)$ \\
\hline \multicolumn{2}{|l|}{ Cardiac } \\
\hline Cardiac arrest requiring CPR & $1(1)$ \\
\hline Sustained hypotension & $2(2)$ \\
\hline \multicolumn{2}{|l|}{ Metabolic } \\
\hline Hyponatremia & $5(4)$ \\
\hline \multicolumn{2}{|l|}{ Others } \\
\hline Blood transfusion & $8(7)$ \\
\hline Death & $7(7)$ \\
\hline Readmission & $14(12)$ \\
\hline
\end{tabular}

CPR: cardiopulmonary resuscitation.

\section{DISCUSSION}

Expeditious surgical care of geriatric hip fractures is gradually being accepted as the standard of care at most centers around the world. ${ }^{7,810)}$ The predominant predictors of adverse effect or mortality after hip fracture surgery in the elderly patients are increasing age, male sex, multiple comorbidities, and ambulatory status after discharge. Time to surgery still remains a contentious factor; some studies categorically showed that when the effects of other confounders were controlled, time to surgery had insignificant effect on mortality after hip fracture surgery. Expeditious surgery (within 24 hours) after hip fracture in the elderly patients is considered the standard of care in the current treatment guidelines of Western countries, whereas in developing countries, like India, expeditious surgery is almost impossible because of the limited presence of health care facilities and poor socioeconomic conditions. However, there are some studies showing mortality could be reduced in elderly patients with hip fracture by addressing comorbidities through co-management, performing surgery in a reasonable time frame (2-3 days), and restoring ambulatory ability. As a military hospital with adequate resources, we were able to institute the GHFP, which include all these aspects of comprehensive geriatric hip fracture care.

In this prospective study, 103 out of 114 patients with hip fracture were evaluated at 1-year follow-up regarding mobility index, complication, and mortality. The mean age of the enrolled patients (77 years) was similar to that in recent studies. ${ }^{11-13)}$ Unlike most other studies where the number of female patients $(80 \%)$ was significantly greater than that of male patients, we had an almost equal number of male (51\%) and female patients. Schnell et al. ${ }^{4)}$ and da Costa et al. ${ }^{14)}$ reported male sex as an adverse predictor of 1-year mortality; on the contrary, in our study, even with a higher proportion of male, the 1-year mortality rate was low. Baseline health status, as assessed by the comorbidity pattern in our study, was similar to that in most other studies where diabetes mellitus and hypertension were most common comorbidities, followed by coronary artery disease; pulmonary and neurological disorders were also reported as the major comorbidities affecting the elderly patients. The average FCI was 1.7 in our patients. Most of the hip fractures in our study (84\%) were due to low-energy falls at home, as in the study by Daniachi et al. ${ }^{13)}$ Therefore, we think that improving home environment to prevent falls in the elderly, as suggested by Siqueira et al. ${ }^{15)}$ and Neto et al., ${ }^{16)}$ is extremely important to decrease the incidence of hip fractures. 
Kulshrestha et al. A Geriatric Hip Fracture Program Report

Clinics in Orthopedic Surgery • Vol. 11, No. 4, $2019 \bullet$ www.ecios.org

Table 4. Comparison with Other Published Studies

\begin{tabular}{|c|c|c|c|c|c|c|}
\hline Study & Type of study & $\begin{array}{l}\text { Mortality } \\
\text { rate }(\%)\end{array}$ & $\begin{array}{l}\text { Total study } \\
\text { population }\end{array}$ & Follow-up & $\begin{array}{l}\text { Mean age } \\
(y r)\end{array}$ & $\begin{array}{l}\text { Mean } \\
\text { length of stay (day) }\end{array}$ \\
\hline Panula et al. $(2011)^{12)}$ & Retrospective cohort study & 27.3 & 428 & $3.7 \mathrm{yr}$ & 82.7 & NA \\
\hline Schnell et al. $(2010)^{4)}$ & Prospective database study & 21.2 & 758 & NA & 84.8 & 4.3 \\
\hline Guerra et.al. $(2016)^{17)}$ & Retrospective study & 23.6 & 199 & NA & NA & NA \\
\hline da Costa et al. $(2009)^{14)}$ & Follow-up evaluation of a cohort & 26.8 & 184 & $12 \mathrm{mo}$ & NA & NA \\
\hline Choi et al. $(2014)^{18)}$ & Multicentric retrospective study & 12.5 & 874 & NA & 77.1 & 24 \\
\hline Wang et al. $(2017)^{19)}$ & Historical cohort study & 1.5 & 410 & $1 \mathrm{mo}$ & 80.32 & NA \\
\hline Daniachi et al. $(2015)^{13)}$ & Prospective observational study & 8 & 113 & NA & 79 & 13.5 \\
\hline Jain et al. $(2015)^{20)}$ & Prospective observational study & 10.9 & 119 & $24 \mathrm{mo}$ & 70.7 & 10.4 \\
\hline Castronuovo et al. $(2011)^{21)}$ & Prospective database cohort study & 30 & 6,896 & $15.8 \mathrm{mo}$ & 83 & NA \\
\hline Lefaivre et al. $(2009)^{22)}$ & Prospective database study & 7.9 & 607 & NA & 83.3 & 23.48 \\
\hline This study & Prospective observational study & 7.7 & 103 & $24 \mathrm{mo}$ & 77 & 7.6 \\
\hline
\end{tabular}

NA: not applicable.

Even with rapid optimization and early surgery, because of delayed presentation (after 48 hours of injury in $50 \%$ of cases) and frequent need for preoperative optimization period ( $>7$ days in $12 \%$ of cases), we could not perform definitive surgery within 24 hours in most cases as recommended by various Western studies. ${ }^{23,24)}$ However, even with the average surgical delay of 3.5 days, the 1-year mortality rate in our study was $7.7 \%$; the rate ranges from $11 \%$ to $26 \%$ in many Western studies (Table 4 ). Even if we presume that all of the patients lost to follow-up (11 patients) had died, the 1-year mortality rate of our study will be less than $18 \%$, which is still comparable to those reported in the Western studies. In another domestic study, Jain et al. ${ }^{20)}$ followed up patients with a very similar geriatric hip fracture. In the study, the 6-month mortality was $6 \%$ and the 2 -year rate was $10.9 \%$, which are comparable to our 1-year rate of $7.7 \%$.

Our study supports the findings of Daniachi et al., ${ }^{13)}$ Choi et al., ${ }^{18)}$ and Guerra et al. ${ }^{17)}$ who reported that time to surgery did not make a significant difference in mortality in elderly patients with hip fracture. They emphasized the importance of optimizing comorbidities in the perioperative period and ensuring independent living at home. Lefaivre et al., ${ }^{22)}$ in their regression analysis, also showed a delay in surgery had no effect on in-hospital mortality when the effects of other confounders were adjusted.

In our study, common postoperative complications encountered were transfusion-requiring anemia $(\mathrm{n}=8$, $7 \%$ ), hyponatremia ( $\mathrm{n}=5,4 \%)$, and superficial surgical site infections ( $\mathrm{n}=4,4 \%$ ); postoperative confusions were encountered in about $3 \%(n=3)$ of the patients. We did not encounter any pulmonary complication. Contrary to our study, increased incidences of pneumonia and pulmonary embolism in the postoperative period were seen in the study published by Choi et al. ${ }^{18)}$ (6.3\% and 5.6\%, respectively). In this study, the delay in surgery was more than 3 days in $80 \%$ of the patients. Despite delayed surgical intervention, pulmonary complications appeared to have been prevented by early co-management of these patients to optimize pulmonary condition with regular nebulization and chest physiotherapy followed by immediate postoperative mobilization.

Wang et al. ${ }^{19)}$ and Castronuovo et al. ${ }^{21)}$ have emphasized the role of home care after discharge and rehabilitation in decreasing 1-year mortality. Our study also strongly supports their conclusion. In the GHFP program, the length of hospital stay is decided by the patient's ability to ambulate and the family members' ability to ensure adequate home care; these goals could be met in our patients because they were treated in the military facility with availability of in-hospital rehabilitation beds. Thus, we could ensure continued independent lifestyle and mobility in these patients as assessed by Parker mobility score (50\% were community ambulators and $45 \%$ were home ambulators) and decrease mortality (two patients) between 3 and 12 months of surgery.

The limitation of our study is that it does not have a comparison group; however, we could compare our 
Kulshrestha et al. A Geriatric Hip Fracture Program Report

Clinics in Orthopedic Surgery • Vol. 11, No. 4, $2019 \bullet$ www.ecios.org

results with those of a number of similar studies already published in the literature. We have instituted a pathway of care for our elderly patients with hip fracture, which facilitated early pain-free mobilization with the restoration of functional status and minimal complications in most patients. In addition, the GHFP enabled cost-efficient treatment. The comprehensive care of geriatric fractures helped us achieve the goal of early surgery, mobilization and discharge to home, and decreased morbidity and mortality. The GHFP should be instituted in all health care settings even in developing countries, notwithstanding the limited health care infrastructure. A trauma team can be set up at the emergency care unit to fast track the fracture fixation. Adverse health conditions at presentation should be recorded and managed expeditiously by a multidisciplinary team. Preoperative optimization of comorbidities, most likely to have an impact on surgery, should take priority; surgery should only follow patient optimization because a reasonable delay in surgery may not affect longterm mortality. Mobility of the patient after discharge has a significant impact on overall mortality; thus, all attempts should be made to restore patient's independent ambulatory ability before discharge to home.

\section{CONFLICT OF INTEREST}

No potential conflict of interest relevant to this article was reported.

\section{ACKNOWLEDGEMENTS}

This research was carried out at Army Hospital with institutional resources.

\section{REFERENCES}

1. Cooper C, Campion G, Melton LJ 3rd. Hip fractures in the elderly: a world-wide projection. Osteoporos Int. 1992;2(6):285-9.

2. Sattin RW. Falls among older persons: a public health perspective. Annu Rev Public Health. 1992;13:489-508.

3. Braithwaite RS, Col NF, Wong JB. Estimating hip fracture morbidity, mortality and costs. J Am Geriatr Soc. 2003;51(3):364-70.

4. Schnell S, Friedman SM, Mendelson DA, Bingham KW, Kates SL. The 1-year mortality of patients treated in a hip fracture program for elders. Geriatr Orthop Surg Rehabil. 2010;1(1):6-14.

5. Wolinsky FD, Fitzgerald JF, Stump TE. The effect of hip fracture on mortality, hospitalization, and functional status: a prospective study. Am J Public Health. 1997;87(3):398403.

6. Johnell O, Kanis JA. An estimate of the worldwide prevalence, mortality and disability associated with hip fracture. Osteoporos Int. 2004;15(11):897-902.

7. Uzoigwe CE, Burnand HG, Cheesman CL, Aghedo DO, Faizi M, Middleton RG. Early and ultra-early surgery in hip fracture patients improves survival. Injury. 2013;44(6):7269.

8. Parker MJ, Palmer CR. A new mobility score for predicting mortality after hip fracture. J Bone Joint Surg Br. 1993;75(5):797-8.

9. Della Rocca GJ, Moylan KC, Crist BD, Volgas DA, Stannard JP, Mehr DR. Comanagement of geriatric patients with hip fractures: a retrospective, controlled, cohort study. Geriatr Orthop Surg Rehabil. 2013;4(1):10-5.

10. Rogers FB, Shackford SR, Keller MS. Early fixation reduces morbidity and mortality in elderly patients with hip fractures from low-impact falls. J Trauma. 1995;39(2):261-5.

11. Aqil A, Hossain F, Sheikh H, Aderinto J, Whitwell G, Kapoor $\mathrm{H}$. Achieving hip fracture surgery within 36 hours: an investigation of risk factors to surgical delay and recommendations for practice. J Orthop Traumatol. 2016;17(3):207-13.

12. Panula J, Pihlajamaki H, Mattila VM, et al. Mortality and cause of death in hip fracture patients aged 65 or older: a population-based study. BMC Musculoskelet Disord. 2011;12:105.

13. Daniachi D, Netto Ados S, Ono NK, Guimaraes RP, Polesello GC, Honda EK. Epidemiology of fractures of the proximal third of the femur in elderly patients. Rev Bras Ortop (English Edition). 2015;50(4):371-7.

14. da Costa JA, Ribeiro A, Bogas M, et al. Mortality and functional impairment after hip fracture: a prospective study in a Portuguese population. Acta Reumatol Port. 2009;34(4):61826.

15. Siqueira FV, Facchini LA, Silveira DS, et al. Prevalence of falls in elderly in Brazil: a countrywide analysis. Cad Saude Publica. 2011;27(9):1819-26.

16. Neto JS, Dias CR, de Almeida JD. Epidemiological characteristics and causes of proximal femoral fractures among the elderly. Rev Bras Ortop. 2015;46(6):660-7.

17. Guerra MT, Viana RD, Feil L, Feron ET, Maboni J, Vargas 
Kulshrestha et al. A Geriatric Hip Fracture Program Report

Clinics in Orthopedic Surgery • Vol. 11, No. 4, $2019 \bullet$ www.ecios.org

AS. One-year mortality of elderly patients with hip fracture surgically treated at a hospital in Southern Brazil. Rev Bras Ortop. 2016;52(1):17-23.

18. Choi HJ, Kim E, Shin YJ, Choi BY, Kim YH, Lim TH. The timing of surgery and mortality in elderly hip fractures: a retrospective, multicenteric cohort study. Indian J Orthop. 2014;48(6):599-604.

19. Wang X, Zhao BJ, Su Y. Can we predict postoperative complications in elderly Chinese patients with hip fractures using the surgical risk calculator? Clin Interv Aging. 2017;12:1515-20.

20. Jain D, Sidhu GS, Selhi HS, et al. Early results of a geriatric hip fracture program in India for femoral neck fracture. Geriatr Orthop Surg Rehabil. 2015;6(1):42-6.
21. Castronuovo E, Pezzotti P, Franzo A, Di Lallo D, Guasticchi G. Early and late mortality in elderly patients after hip fracture: a cohort study using administrative health databases in the Lazio region, Italy. BMC Geriatr. 2011;11:37.

22. Lefaivre KA, Macadam SA, Davidson DJ, Gandhi R, Chan $\mathrm{H}$, Broekhuyse HM. Length of stay, mortality, morbidity and delay to surgery in hip fractures. J Bone Joint Surg Br. 2009;91(7):922-7.

23. Bottle A, Aylin P. Mortality associated with delay in operation after hip fracture: observational study. BMJ. 2006;332(7547):947-51.

24. Simunovic N, Devereaux PJ, Bhandari M. Surgery for hip fractures: does surgical delay affect outcomes? Indian J Orthop. 2011;45(1):27-32. 